\title{
DEVELOPMENT AND TEST RUN OF CIVIL ENGINEERING SCHEDULE ACCELERATION MODEL THROUGH ANT COLONY OPTIMIZATION
}

\author{
Chen WANG ${ }^{\mathrm{a}, \mathrm{b}}$, Hamzah ABDUL-RAHMAN ${ }^{\mathrm{c}}$, Pui See CHOW \\ ${ }^{a}$ Faculty of Built Environment, University of Malaya, 50603, Kuala Lumpur, Malaysia \\ ${ }^{b}$ Faculty of Civil Engineering, Huaqiao University, 361021 Xiamen, China \\ ${ }^{c}$ Vice Chancellor's Office, International University of Malaya-Wales, Kuala Lumpur, Malaysia
}

Received 21 Mar 2014; accepted 22 May 2014

\begin{abstract}
The traditional scheduling tool Critical Path Method (CPM) exhibits limitations in computational insufficiency due to exhaustive enumeration. Ant Colony Optimization (ACO) was therefore applied as a metaheuristic inspired by the ants behavior in foraging activities. A model development team was formed among construction engineers, IT professionals, and Mathematicians to develop a schedule acceleration model by integrating ACO into CPM to ensure proper resources allocated on critical path. The developed model CSAM-ACO targets on schedule acceleration by allocating resources on the newly found critical path after two stages of computation. The trial run proved CSAM-ACO model more favorable compared with CPM.
\end{abstract}

Keywords: Ant Colony Optimization (ACO), Critical Path Method (CPM), construction schedule acceleration, ACO algorithm, exhaustive enumeration.

\section{Introduction}

In 1992, Marco Dorigo proposed an efficient metaheuristic technique for solving computational problems to find good paths through graphs, which is called Ant Colony Optimization (ACO) inspired by the foraging behavior of real ant colonies (Duan, Liao 2010; Zundel 2013; Al Salami 2009). Due to its benefit in solving difficult combinatorial problems, many researchers have presented the application of ACO in management of construction projects especially in large and complex projects (Srour et al. 2013; Lopez-Ibanez, Blum 2010). ACO could be applied in resources management (Christodoulou 2009), determining project critical paths (Duan, Liao 2010), construction site layout planning (Lam et al. 2007), optimizing construction time and cost (Ng, Zhang 2008), and management of time-cost-risk trade off (Lakshminarayanan et al. 2011). ACO is also proposed in construction project scheduling owing to the fact that the real ant colonies exhibit a behavior that is suitable to optimal network traversing and to find the longest path in scheduling (Mateos et al. 2013). Recently, the formulation of ACO algorithms in solving the resource-unconstrained schedule and determining of project critical paths have great contributions to the scheduling technique (Hani et al. 2007; Mubarak 2010; Kloppenborg 2009). The ACO alternative provides powerful way in construction scheduling with quick convergence to the final solution so that it can be applied to deal with more realistic project scheduling problems to take into account the inevitable situation to make the construction works in faster track (Sauter 2011; Naylor 1995).

Therefore, this research is focused on rescheduling critical tasks by integrating ACO into CPM in construction schedule acceleration. The aim of this study is to develop a schedule acceleration model, based on ACO and CPM, to assist construction practitioner in schedule acceleration to ensure proper resources allocated on critical path. Eventually, the developed model deems to increase the probability to complete a delayed project within the stipulated time and to satisfy the request of an earlier completion of project.

\section{Ant Colony Optimization (ACO) and application in construction}

Ants are undoubtedly one of the most successful species on the earth today and they have been so 100 million years (Dorigo, Stutzle 2004). It is not surprising that the increasing design of algorithms inspired from the behavior of ants. The first ACO system was introduced by Marco Dorigo from Italy in his $\mathrm{PhD}$ dissertation in 1992 and it is also called as Ant System (AS) (Dorigo 1992). ACO transforms the model of collective intelligence of ants into optimization algorithms (Dorigo, Blum 2005). ACO has been applied in solving many combinatorial op-

Corresponding author: Chen Wang

E-mail:derekisleon@gmail.com 
timization problems such as travelling salesman (Dorigo, Gambardella 1997), graph coloring (Costa, Hertz 1997), vehicle routing (Dorigo et al. 2000), feature selection (Duan, Liao 2010), and quadratic assignment problem (Wiesemann, Stutzle 2006).

In ACO, a colony of biological ants is typically modeled by a society of artificial agents and those agents build solutions by making path traversing on the directed acyclic network. Dorigo et al. (1999) defined ACO as a population-based general search technique for the solution of difficult combinatorial problems. This metaheuristic technique is inspired by the behavior exhibited by real ant colonies proposed by Dorigo with the concept of pheromone trail laying (Dorigo, Stutzle 2004). The main idea of ACO is the cooperation of a number of artificial ants via pheromone laid on path where each ant contributes a little effort to the solution construction, while the final result is an emergence of the ants' interaction (Hoseini, Shayesteh 2013; Kong, Tian 2006). This method is inspired by the foraging behavior of ants so that it presents a highly structured organization, which is able to accomplish complex tasks that is far exceed compared with the individual capabilities of a single ant.

\subsection{Variations of $\mathrm{ACO}$ algorithms}

In general, the variants of the ACO algorithm are differed from each other in the pheromone update rule applied (Dorigo, Blum 2005). There are several extensions and improvements of the original algorithm introduced over the years for the adoption to more combinatorial optimization, namely: Elitist Ant System (EAS) (Dorigo et al. 1996), Rank-based Ant System (RAS) (Bullnheimer et al. 1997), MAX-MIN Ant System (MMAS) (Stutzle, Hoos 2000), Ant Colony System (ACS) (Dorigo, Gambardella 1997), Hyper-Cube Framework (FCF) (Blum, Dorigo 2004), Ant System (AS) (Dorigo et al. 1996), and BestWorst Ant System (BWAS) (Cordon et al. 2002).

\subsection{Application of ACO Algorithms}

The ACO metaheuristic introduced by Dorigo has been successfully applied to a large number of combinatorial optimization problems. The travelling salesman problem (TSP) was the first problem tackled by the ACO algorithm because this problem is suitable to adopt a real ant's behavior to solve it with the constraint shortest path (Dorigo et al. 1999). ACO was also used for machine learning purposes, concretely to the design of learning algorithms for knowledge representation structures such as classical logic rules (Parpinelli et al. 2002), fuzzy logic rules (Alcala et al. 2001), and Bayesian networks (Campos et al. 2002). Table 1 shows a summary of various ACO applications.

\subsection{Ant Colony Optimization in construction scheduling}

Christodoulou (2009) outlined the steps in finding the critical path by using ACO algorithms. Firstly, all the arcs
Table 1. Various applications of ACO algorithms

\begin{tabular}{|c|c|c|}
\hline Applications & Authors & Algorithm S \\
\hline $\begin{array}{l}\text { Travelling } \\
\text { Salesman } \\
\text { Problem } \\
\text { (TSP) }\end{array}$ & $\begin{array}{l}\text { Dorigo et al. (1996) } \\
\text { Gambardella and } \\
\text { Dorigo (1996) } \\
\text { Dorigo and } \\
\text { Gambardella (1997) } \\
\text { Stutzle and Hoos } \\
\text { (2000) } \\
\text { Bullnheimer et al. } \\
\text { (1997) } \\
\text { Blum and Lopez-Ibanez } \\
(2010)\end{array}$ & $\begin{array}{l}\text { AS } \\
\text { Ant-Q } \\
\text { ACS \& ACS-3-opt } \\
\text { MMAS } \\
\text { RAS } \\
\text { Beam-ACO }\end{array}$ \\
\hline $\begin{array}{l}\text { Quadratic } \\
\text { Assignment } \\
\text { Problem } \\
\text { (QAP) }\end{array}$ & $\begin{array}{l}\text { Maniezzo and Colorni } \\
(1999) \\
\text { Gambardella and } \\
\text { Dorigo (1996) } \\
\text { Stutzle and Hoos } \\
\text { (2000) } \\
\text { Maniezzo and Colorni } \\
\text { (1999) } \\
\text { Wiesemann and Stutzle } \\
(2006)\end{array}$ & $\begin{array}{l}\text { AS-QAP } \\
\text { HAS-QAP } \\
\text { MMAS-QAP } \\
\text { ANTS-QAP \& AS- } \\
\text { QAP } \\
\text { MMAS-QAP }\end{array}$ \\
\hline $\begin{array}{l}\text { Vehicle } \\
\text { Routing } \\
\text { Problem } \\
\text { (VRP) }\end{array}$ & $\begin{array}{l}\text { Bullnheimer et al. } \\
\text { (1997) } \\
\text { Li and Tian (2006) }\end{array}$ & $\begin{array}{l}\text { AS-VRP } \\
\text { ACS-OVRP }\end{array}$ \\
\hline $\begin{array}{l}\text { Connection- } \\
\text { oriented } \\
\text { network } \\
\text { routing } \\
\end{array}$ & $\begin{array}{l}\text { Schoonderwoerd et al. } \\
\text { (1996) } \\
\text { Caro and Dorigo (1998) }\end{array}$ & $\begin{array}{l}\text { ABC } \\
\text { AntNet-FS }\end{array}$ \\
\hline $\begin{array}{l}\text { Graph } \\
\text { coloring }\end{array}$ & Costa and Hertz (1997) & ANTCOL \\
\hline
\end{tabular}

or connectors in the network are initialized with pheromone, $\tau_{0}$ which is the value of the inverse line-distance between the nodes or the inverse line-distance of the particular arc. After that, an artificial ant is launched from a start node and pseudo-randomly walking from a node to a successor node passed through the connecting arcs until it reaches the end-node or dead end. However, the previously selected arcs are excluded from the selection for "tree spanning" and avoid memorization. The artificial ant's selection for the successor node to follow is probabilistic which is based on the stochastic assignment of each arc's selection defined by Eqn (1):

$$
P_{i}=\frac{\tau_{i} \eta_{i}^{\beta}}{\Sigma \tau_{i} \eta_{i}^{\beta}},
$$

where $\tau_{i}$ is the pheromone concentration on the $i^{\text {th }}$ arc, $\eta_{i}$ is a priori available heuristic value which allows incorporation of problem specific information for the $i^{\text {th }}$ arc, defined as the length of the inverse arc or the length of the inverse arc plus the line-distance between the nodes. $\beta_{i}$ is a parameter determining the relative influence of the heuristic information. Moreover, the selection is also assisted by the consideration of a randomly generated number $q(0 \leq q \leq 1)$ to compare with a predefined value which is specific to the network topology $q_{0}$. By using this network topology, if $q \leq q_{0}$, the arc with the highest 
probability will be selected. Otherwise, the arc is selected randomly based on the distribution defined by Eqn (1). A local pheromone update rule is applied to update the pheromone concentration level of a given arc, when the ants crossing each of the arcs during the construct solution phase. The purpose of this update rule is to enable exploration of more paths or routes to give the already visited arcs less chance to be selected during the randomization of the arc selection process. The local update pheromone is defined by Eqn (2):

$$
\tau_{i}=(1-\rho) \tau_{i}+\rho \tau_{0},
$$

where $\rho$ is another network topology parameter $(0 \leq \rho \leq 1)$. In this procedure, stochastic decision process and local pheromone update rule will be repeated for all ants in the colony and the most successful ant is used in global pheromone update to update the pheromone level of the network defined by Eqn (3):

$$
\tau_{i}=(1-\alpha) \tau_{i}+\alpha \tau_{L},
$$

where $\alpha$ is used to determine the level of evaporation of pheromone concentration and $\tau_{L}$ is a value that inversely proportional to the path length of the best solution in case of an arc visited by the best ant or zero for other ants $(0 \leq \alpha \leq 1)$. Here, the global pheromone update rule can be applied by using either "global-best" or "iterationbest" ant. In "global-best" ant, the ant that obtained the best solution which is the longest path in the network during optimization process is the one who perform the update. In the other hand, the "iteration-best" is performed by the ant who reaching the best solution during each iteration. All the steps from the probabilistic rule to pheromone update rule that include the local pheromone update and global pheromone update are repeated until a fixed number of iteration or a predefined conditions is met, and upon the termination of the algorithm the pheromone trail is used to determine the solution where the arc with the highest pheromone concentration level is defined as the longest path in the network.

\section{Research procedures and model development}

Owing to the nature of the research where people's experiences, perceptions, opinions and knowledge are necessities to the development of the model, qualitative approach is employed in this study, which consists of the following five stages. The first stage reasoned the selection of ACO algorithms in schedule acceleration. The second stage worked out the ACO algorithm processes used for the development of the final CSAM-ACO acceleration model. In the third stage, each step of the final model was developed and outlined. The complete CSAM-ACO acceleration model associated with its main components was finalized on the fourth stage. The final but significant stage is the trial run of the developed CSAM-ACO model using a real high rise building project. This qualitative technique enables any misunderstanding or intangible issues to be avoided so that the model development pro- cess can be rectified immediately. A development team was formed among experts from various fields such as construction engineers, IT professionals, and Mathematicians, whose profiles are presented in Table 2. Extensive data are collected through the development process. A trial run of the CSAM-ACO model was conducted to test how it works in a real situation. Prior to the commencement of trial run, a pilot study was carried out to identify the most commonly delay activity for high rise buildings. The ACO algorithm processes for the final CSAM-ACO acceleration model consists of 7 steps as follows.

\section{Step 1: Establish network topology}

Network topology is used in presenting the precedence relationship of the construction activities. In a construction project, the network topology provides a comprehensive layout for project schedule with a set of activities related to one another. There are two types of network diagrams, namely: activity-on-node (AON) and activity-on-arrow (AOA). For an AON network, the node represents the activity and the arc represents the precedence relationship among the activities. On the other hand, the node in an AOA network represents the event and the arc represents the activity. In this study, the activities in a real construction are represented by letters in the network diagram and the purpose of using different letters to represent the activities is to show a real scenario of various activities in the construction process. The project network topology in this study is defined by an AON graph $G=(N, A)$ where a finite set of components is given, where $N=\{1,2,3, \ldots, n\}$ is the set of nodes representing the activities, and $\mathrm{A}$ is a set of arcs representing the relationship among the nodes. The established network topology is analyzed to initialize the topology parameters in the next step.

\section{Step 2: Initialize topology parameters}

The choice of topology parameters is based on a sensitivity analysis on other randomized topologies and the observed accuracy of convergence to an optimal solution. There are four common parameters for ACO algorithm in finding the critical path, namely: i) $q_{0}$, which assists the selection of path based on probability or random selection; ii) $\rho$, which determines the level of evaporation of pheromone concentration for local update; iii) $\alpha$, which determines the level of evaporation of pheromone concentration for global update, and iv) $\beta$, which determines the relative influence of the heuristic information. The established network diagram shows the complexity of the project by sequencing out the activities.

\section{Step 3: Set initial pheromone level}

At this step, the artificial ants are expected to search the path randomly because no previously visited arc with higher pheromone concentration can be detected by them. Hence, the initial levels of pheromone concentration of all arcs are set to an equal small constant value as the 
Table 2. Profiles of CSAM-ACO development team

\begin{tabular}{|c|c|c|c|c|c|}
\hline No & Age & Gender & Specialty/area & & Roles in model development \\
\hline $\mathrm{i}$ & 34 & Male & $\begin{array}{l}\text { Project } \\
\text { Monitoring }\end{array}$ & $\begin{array}{l}\text { Stage } \\
1 \& 5\end{array}$ & $\begin{array}{l}\text { Reasoning the selection of ACO algorithms in schedule acceleration. } \\
\text { Developer i examined the limitation of traditional CPM a) CPM is unable } \\
\text { to calculate the longest or shortest paths from a node to any node; b) CPM } \\
\text { does not take into consideration the resource-driven relationships for } \\
\text { the activities; and c) The computational insufficiency of CPM due to } \\
\text { exhaustive enumeration. He was also in charge of the CPM calculation part } \\
\text { in the trial run. The critical path of the project was identified by both the } \\
\text { traditional CPM and the new ACO approach to verify the application of } \\
\text { ACO in finding the critical path. }\end{array}$ \\
\hline ii & 46 & Male & $\begin{array}{l}\text { Construction } \\
\text { IT Application }\end{array}$ & $\begin{array}{l}\text { Stage } \\
1 \& 5\end{array}$ & $\begin{array}{l}\text { Reasoning the selection of ACO algorithms in schedule acceleration. } \\
\text { Developer ii was in charge of finding the critical path of the project by } \\
\text { calculating the total float. }\end{array}$ \\
\hline iii & 31 & Female & Mathematician & $\begin{array}{l}\text { Stage } \\
2\end{array}$ & $\begin{array}{l}\text { Worked out the ACO algorithm processes for the development of the } \\
\text { final CSAM-ACO acceleration model. She was in charge of establishing } \\
\text { network topology, initializing topology parameters, setting initial } \\
\text { pheromone level, and constructing best solution. }\end{array}$ \\
\hline iv & 57 & Male & $\begin{array}{l}\mathrm{ACO} \\
\text { algorithms }\end{array}$ & $\begin{array}{l}\text { Stage } \\
2 \& 5\end{array}$ & $\begin{array}{l}\text { He was in charge of local pheromone update rule, global pheromone } \\
\text { update, and reach number of iterations and termination. }\end{array}$ \\
\hline $\mathrm{v}$ & 42 & Male & Mathematician & Stage 3 & $\begin{array}{l}\text { Each step of the final CSAM-ACO acceleration model was developed. He } \\
\text { was in charge of selecting critical activities and splitting critical activities. }\end{array}$ \\
\hline vi & 29 & Female & Mathematician & $\begin{array}{l}\text { Stage } \\
3 \& 5\end{array}$ & $\begin{array}{l}\text { She was in charge of finding critical path from critical tasks. He was also } \\
\text { the main programmer of the model trial run. }\end{array}$ \\
\hline vii & 35 & Male & Modelling & $\begin{array}{l}\text { Stage } \\
4\end{array}$ & $\begin{array}{l}\text { The complete CSAM-ACO acceleration model associated with its main } \\
\text { components was graphed and finalized by him. }\end{array}$ \\
\hline viii & 38 & Male & $\begin{array}{l}\text { Project } \\
\text { Manager }\end{array}$ & $\begin{array}{l}\text { Stage } \\
5\end{array}$ & $\begin{array}{l}\text { He is the project manager of the high rise building project used for CSAM- } \\
\text { ACO trial run. All the on-site data were provided by him. He supervised } \\
\text { the trial run of the developed CSAM-ACO model on a high rise building } \\
\text { project. }\end{array}$ \\
\hline ix & 43 & Male & $\begin{array}{l}\text { Cartographer } \\
\& \text { ACO } \\
\text { algorithms }\end{array}$ & $\begin{array}{l}\text { Stage } \\
4 \& 5\end{array}$ & $\begin{array}{l}\text { All the on-site data provided by the Developer viii were translated and } \\
\text { inputted by Developer ix into the CSAM-ACO. He is the cartographer of } \\
\text { the iteration diagrams. }\end{array}$ \\
\hline
\end{tabular}

initial pheromones laid on the connections. The pheromone level of all arcs in the network topology is initialized with small amounts of pheromone $\tau_{0}$.

\section{Step 4: Construct best solution}

After the initial pheromone level is set, an ant population is allocated. The ant population starts to walk randomly from the initial node to the end node or dead end via the connecting arcs. The artificial ants moving on the directed cyclic graph will build either feasible or infeasible solutions but in general, the feasible solutions will try to be built. At each node, the artificial ants will select the edge to move from one node to any other nodes following the probability defined by Eqn (1).

\section{Step 5: Local pheromone update rule}

After crossing each arc of the network, the local pheromone update rule is applied to update the level of pheromone at the given arc. The evaporation of pheromone is updated by the means of local pheromone update applied to all paths. The local pheromone update rule is defined by Eqn (2).

\section{Step 6: Global pheromone update}

Global pheromone update applies to the best path of the iteration. The longest path made by an ant in the par- ticular iteration is the best path plus an amount of pheromone concentration on the travelled path where the linedistance of that path is increasing. The most frequently chosen path of the iterations has the highest pheromone concentration. Therefore, the longest path can be found when reaching the fixed number of iterations after the global pheromone update rule is applied. The global pheromone update is defined by Eqn (3).

\section{Step 7: Reach number of iterations and termination}

The ACO algorithm process comes to the end when a fixed number of iterations are reached after repeating step 4 to step 6 . The best solution is found from the final pheromone level and the chosen probability of the nodes. The ACO algorithm processes for the development of the final CSAM-ACO acceleration model is summarized in Figure 1.

\section{Appearance of developed CSAM-ACO acceleration model}

\section{Step 1: Finding critical path of project}

The critical path of a project is identified through the calculation of total float. CPM is performed to calculate the forward pass and the backward pass. Eqn (4) to Eqn (7) are applied in the computational process of CPM: 


$$
\begin{gathered}
E F_{i}=E S_{i}+\text { duration of activity; } \\
L S_{i}=L F_{i}-\text { duration of activity; } \\
T F=L F-E F / L S-E S ; \\
T F=L F-E S-\text { duration. }
\end{gathered}
$$

In the developed model, ACO algorithm was applied to tackle the computational problem of CPM. The first step of the developed CSAM-ACO acceleration model is to find the critical path using ACO algorithm process and to compare the computational time and result with that of using CPM.

\section{Step 2: Selection of critical activities}

The duration of the critical path equals to the duration of the entire project, hence shortening of project duration can be achieved by shortening the duration of the criti- cal path. To shorten the duration of the longest path, the duration of the critical activities can be reduced by using the method of crashing or splitting of task. If a project is delayed, more additional works need to be completed within the stipulated time, or same amount of works need to be performed in a shorter duration.

\section{Step 3: Splitting of critical activities}

This step is to rearrange activities by splitting or crashing them into smaller tasks. The smaller tasks are presented in a new network topology which represents the relationship of the tasks and the durations, respectively. The crashing of critical activities has an advantage in reducing the total completion period by rescheduling all the possible tasks that can be completed concurrently. By doing this, more successor tasks can be completed without waiting for the completion of predecessor task if it is an independent task.

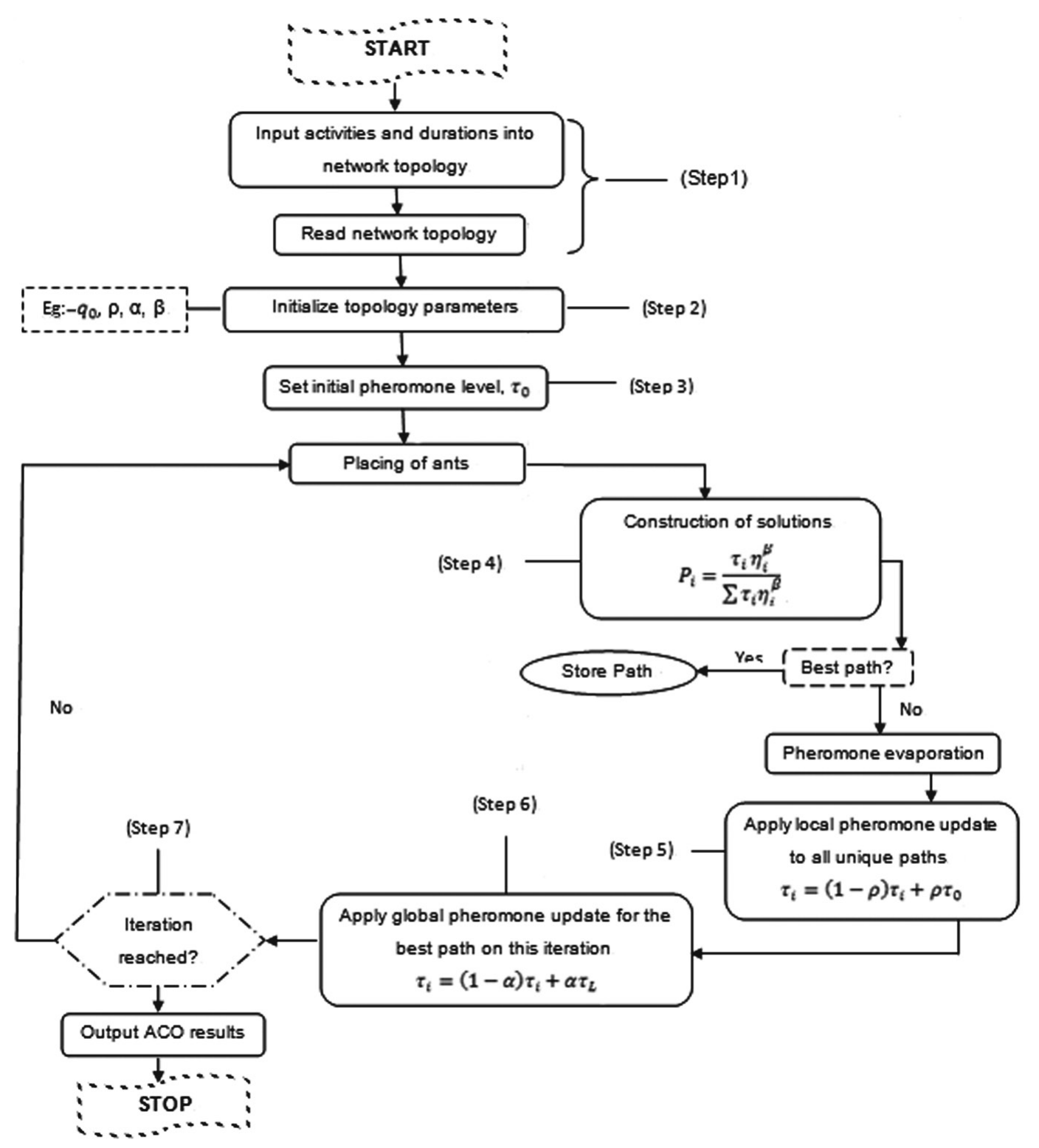

Fig. 1. ACO algorithm processes for the development of CSAM-ACO acceleration model 


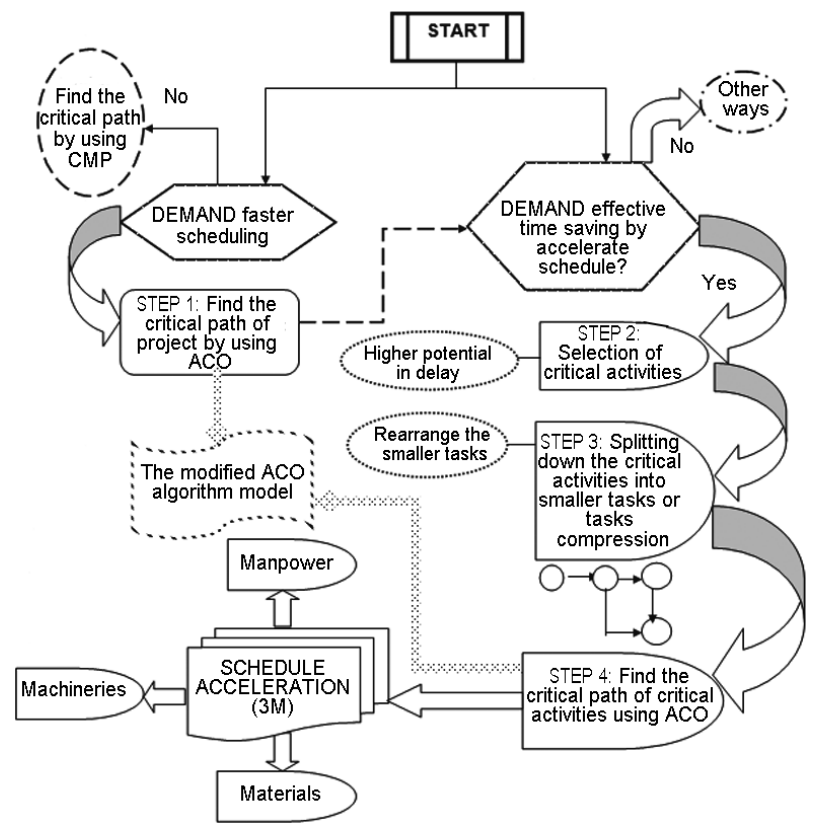

Fig. 2. Appearance of Final CSAM-ACO

\section{Step 4: Find critical path from critical tasks}

The critical path of a project is determined in Step 1 and is splitting into smaller tasks or is compressed in Step 3. A new critical path is then determined from the smaller tasks that indicate the shortest duration of its particular critical activity. The project managers would pay more attention to the new critical path when conducting resource and cost allocation to ensure the tasks in the critical activity not to be delayed; otherwise it will lead to the delay of the whole activity and thus the entire project. The detailed activities help resources be allocated precisely. The final developed CSAM-ACO acceleration model is illustrated in Figure 2.

\section{Trial run of developed CSAM-ACO model}

A high rise construction project in the urban area was chosen for the trial run of the developed CSAM-ACO. The case is concerned with a top level construction company dealing with the client to construct an office building at Subang Jaya, Malaysia, and time is one of the main concerns. The goal is to find the critical path and to split down the critical activities into smaller tasks by taking into consideration the resource allocation to shorten the project duration.

\section{Step 1: Find the critical path}

In the trial run, the critical path of the project was identified by both the traditional CPM and the ACO approach. Activities are graphed in the network topology. Table 3 shows the activities in the high rise project and Figure 3 illustrates the network diagram. The trial run is based on the topology with 8 nodes and 12 nodal connections. Among the 8 nodes in the network topology, there are 2 ant nests, 1 food source and 5 regular nodes. The
Table 3. Activities with precedence relationships and durations

\begin{tabular}{l|l|c|c|c}
\hline $\begin{array}{c}\text { Activity } \\
\text { code }\end{array}$ & \multicolumn{1}{|c}{$\begin{array}{c}\text { Activity } \\
\text { name }\end{array}$} & $\begin{array}{c}\text { Durations } \\
\text { (days) }\end{array}$ & Predecessor & Successor \\
\hline A: $0-2$ & $\begin{array}{l}\text { Mobilize on } \\
\text { site }\end{array}$ & 10 & - & F, G, H \\
\hline B: 0-3 & $\begin{array}{l}\text { Factory } \\
\text { fabrication }\end{array}$ & 70 & - & I \\
\hline C: $0-4$ & $\begin{array}{l}\text { Demolition } \\
\text { and site } \\
\text { clearing }\end{array}$ & 33 & - & J \\
\hline D: $1-4$ & Earthworks & 29 & - & E, J \\
\hline E:1-5 & Install utilities & 43 & - & K \\
\hline F: 2-3 & Frame & 70 & A & I \\
\hline G: $2-6$ & Foundation & 67 & A & L \\
\hline H: $2-7$ & $\begin{array}{l}\text { Doors and } \\
\text { windows }\end{array}$ & 78 & A & - \\
\hline I: $3-7$ & Roofing & 67 & B, F & - \\
\hline J: 4-6 & Excavation & 37 & C, D & L \\
\hline K: $5-7$ & Plastering & 11 & E & - \\
\hline L: 6-7 & Piling & 29 & G, J & - \\
\hline
\end{tabular}

node with no predecessor node represents ant nest whereas food source with no successor node. A generated network is based on unidirectional nodal connections, which is an acyclic graph to imitate the real life of construction activity.

\section{By Traditional Method: CPM}

The earliest start (ES), earliest finish (EF), latest start (LS), and latest finish (LF) were calculated. All the possible paths were found along the way. The activity with zero total float is the critical activity. The calculation using traditional CPM is shown in Table 4. The results of calculated ES, EF, LS, LF and total float by using CPM method are tabulated in the Table 5. The critical path formed by the critical activities $0-2,2-3,3-7$ with zero total float. Thus, the longest project total duration is $70+70+67=207$ which equals to the shortest duration to complete the entire project.

\section{By ACO Algorithm}

Applying the developed ACO algorithm process, the network topology parameters are identified in Table 6.

The pheromone level of all the arcs are same at this stage since there is no path yet travelled by ants so far. However, each arc has a small value of pheromone concentration to initialize the selection process where the ant moves randomly to choose the path to travel. The value of the initial pheromone level was set according to the line-distance between the nodes. It is either the inverse line-distance between two nodes or the inverse line-distance of the arc between the nodes. The line-distance in the construction network topology represents the duration of the activity. The path chosen is based on the probability calculated by Eqn (1). Ten iterations were completed and the final pheromone level was established in Table 7. The highest probability indicates the longest path of the network which is the critical activity, and the highest 


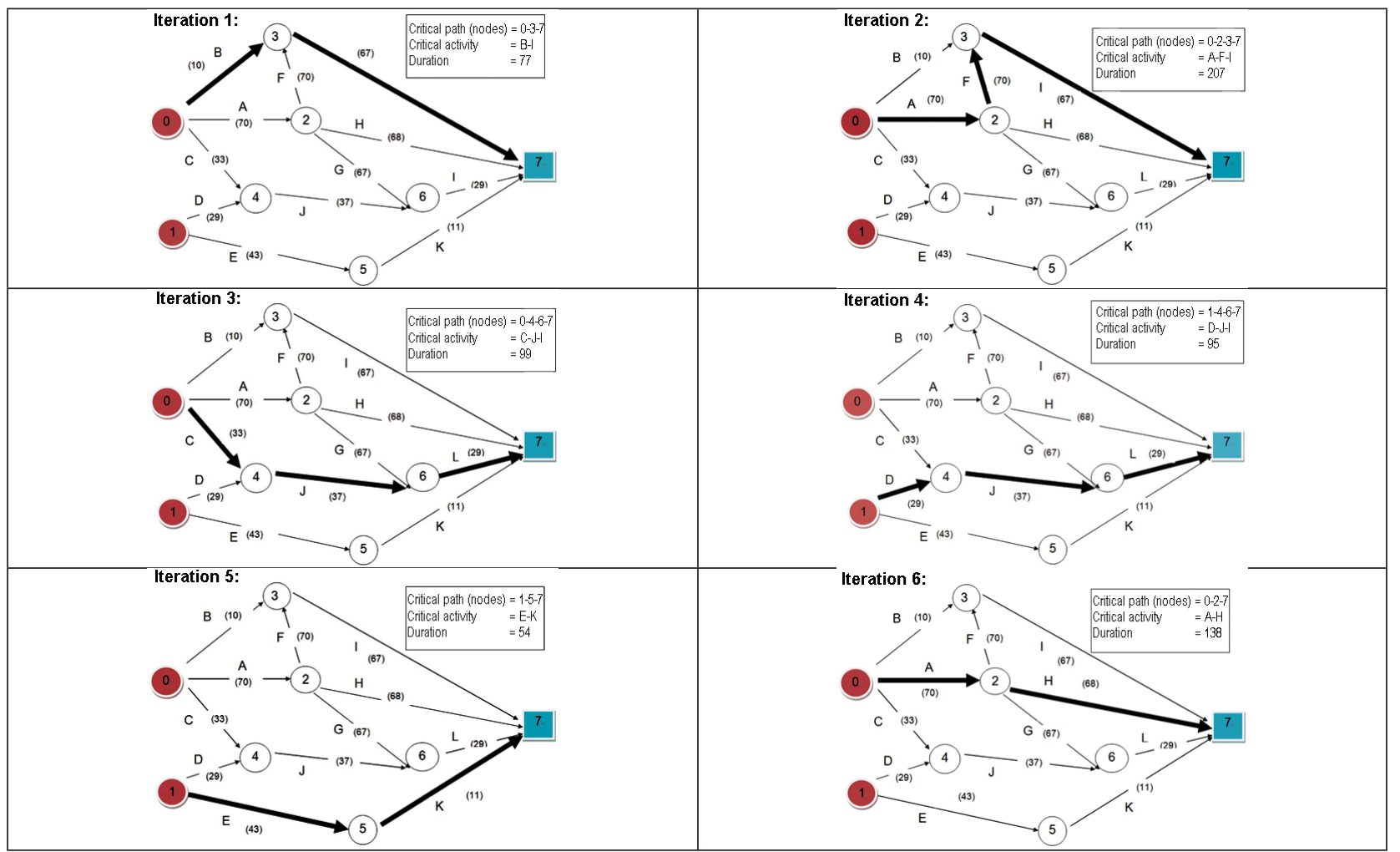

Fig. 3. Network topology for Iteration 1 to Iteration 6

Table 4. Calculation using traditional CPM for trial run

\begin{tabular}{|c|c|c|}
\hline Calculation of forward pass & Calculation of backward pass: & Calculation of total float \\
\hline $\mathrm{EF}_{\mathrm{i}}=\mathrm{ES}_{\mathrm{i}}+$ duration of activity & $\mathrm{LS}_{\mathrm{i}}=\mathrm{LF}_{\mathrm{i}}-$ duration of activity & $\begin{array}{l}\mathrm{TF}=\mathrm{LF}-\mathrm{EF} / \mathrm{LS}-\mathrm{ES} \\
\text { or } \mathrm{TF}=\mathrm{LF}-\mathrm{ES}-\text { duration }\end{array}$ \\
\hline $\begin{array}{l}\text { Activity A: } \\
\text { The ES for activity A is zero because the } \\
\text { node with no predecessor. Thus, } \\
\mathrm{EF}_{\mathrm{A}}=\mathrm{ES}_{\mathrm{A}}+\text { duration }=0+70=70\end{array}$ & $\begin{array}{l}\text { Activity } L \text { : } \\
\mathrm{LF} \text { of activity } \mathrm{L} \text { is the largest value of } \\
\text { the EF since activity } \mathrm{L} \text { is one of the last } \\
\text { activities that has the largest value of EF. } \\
\text { Thus, } \\
\mathrm{LS}_{\mathrm{L}}=\mathrm{LF}_{\mathrm{L}}-\text { duration }=207-29=178\end{array}$ & $\begin{array}{l}\text { Activity } A \text { : } \\
\text { TF }=\mathrm{LF}-\mathrm{EF} / \mathrm{LS}-\mathrm{ES} \\
=70-70 / 0-0=0\end{array}$ \\
\hline $\begin{array}{l}\text { Activity } F \text { : } \\
\text { For the activity with only one predecessor, } \\
\text { the ES of activity } \mathrm{F} \text { is the EF of the } \\
\text { predecessor. Thus, } \\
\mathrm{EF}_{\mathrm{F}}=\mathrm{ES}_{\mathrm{F}}+\text { duration }=70+70=140\end{array}$ & $\begin{array}{l}\text { Activity } J \text { : } \\
\text { Activity } J \text { with only one successor, the LF } \\
\text { of the activity } J \text { is the LS of the successor. } \\
\text { Thus, } \\
\mathrm{LS}_{\mathrm{j}}=\mathrm{LF}_{\mathrm{j}} \text { - duration }=178-37=141\end{array}$ & $\begin{array}{l}\text { Activity } B \text { : } \\
\text { TF }=\mathrm{LF}-\mathrm{ES}-\text { duration } \\
=140-0-10=130\end{array}$ \\
\hline $\begin{array}{l}\text { Activity J: } \\
\text { For the activity with more than one or more } \\
\text { predecessor, the smallest value was chosen. } \\
\text { There are two choices of EF for activity J: } \\
33 \text { and } 29 \text {, the smallest EF } 29 \text { was chosen as } \\
\text { the ES of activity J. Thus, } \\
\mathrm{EF}_{\mathrm{J}}=\mathrm{ES}_{\mathrm{J}}+\text { duration }=29+37=66\end{array}$ & $\begin{array}{l}\text { Activity A: } \\
\text { For the activity with more than one or } \\
\text { more successor, the smallest value of the } \\
\text { LS was chosen. There are three choices } \\
\text { of EF for activity A: } 10,41 \text { and } 79 \text {, the } \\
\text { smallest EF is chosen as the LF of activity } \\
\text { A. Thus, } \\
\text { LS }_{\mathrm{A}}=\mathrm{LF}_{\mathrm{A}}-\text { duration }=70-70=0\end{array}$ & $\begin{array}{l}\text { It shows that the activity B is } \\
\text { not critical activity with total } \\
\text { float of } 130 \text { whereas the activity } \\
\text { A is the critical activity with } \\
\text { zero value of the total float. }\end{array}$ \\
\hline
\end{tabular}

pheromone concentration is the shortest distance where the ant moves on.

The ACO algorithms generated different states of topology at the end of each iteration, because each successive iterative is selective based on the previously selected arc. Therefore, the critical path may change a few times before the last iteration. The network topologies for iteration 1 to iteration 6 are illustrated in Figure 3 and the final result is presented in Figure 4. The pheromone concentration is used to indicate the criticality of the activities as shown in Table 8. The "final pheromone level" or "probability" is the value to decide which activities are critical. The longest continuous path was identified and the activities of $0-2,2-3$, and 3-7 are the critical activities with the critical path duration at 207. 
Table 5. Critical path using CPM

\begin{tabular}{c|c|c|c|c|c|c|c|c|c|c}
\hline No & Start node & End node & Duration & Successor & ES & EF & LS & LF & TF & Critical activity \\
\hline A & 0 & 2 & 70 & F, G, H & 0 & 70 & 0 & 70 & 0 & YES \\
\hline B & 0 & 3 & 10 & I & 0 & 10 & 130 & 140 & 10 & No \\
\hline C & 0 & 4 & 33 & J & 0 & 33 & 108 & 141 & 48 & No \\
\hline D & 1 & 4 & 29 & E, J & 0 & 29 & 112 & 141 & 52 & No \\
\hline E & 1 & 5 & 43 & K & 0 & 43 & 153 & 196 & 93 & No \\
\hline F & 2 & 3 & 70 & I & 70 & 140 & 70 & 140 & 0 & YES \\
\hline G & 2 & 6 & 67 & L & 10 & 77 & 111 & 178 & 31 & No \\
\hline H & 2 & 7 & 68 & - & 10 & 78 & 139 & 207 & 89 & No \\
\hline I & 3 & 7 & 67 & - & 140 & 207 & 140 & 207 & 0 & YES \\
\hline J & 4 & 6 & 37 & L & 29 & 66 & 141 & 178 & 52 & No \\
\hline K & 5 & 7 & 11 & - & 43 & 54 & 196 & 207 & 93 & No \\
\hline L & 6 & 7 & 29 & - & 66 & 95 & 178 & 207 & 52 & No \\
\hline
\end{tabular}

Table 6. The identified network topology parameters

\begin{tabular}{c|l}
\hline$q_{0}=0.3$ & assist the selection of path based on the probability or random selection \\
\hline$\rho=0.5$ & determine the level of evaporation of pheromone concentration for local update \\
\hline$\alpha=1.0$ & determine the level of evaporation of pheromone concentration for global update \\
\hline$\beta=1.0$ & determine the relative influence of the heuristic information \\
\hline
\end{tabular}

Table 7. Probability \& pheromone level of $0-2,0-3,0-4$

\begin{tabular}{|c|c|c|c|c|c|c|}
\hline \multirow{2}{*}{$\begin{array}{l}\text { No. of } \\
\text { iteration }\end{array}$} & \multicolumn{2}{|r|}{$0-2$} & \multicolumn{2}{|r|}{$0-3$} & \multicolumn{2}{|r|}{$0-4$} \\
\hline & $\begin{array}{c}\text { Probability, } \\
\mathrm{P}_{02}\end{array}$ & $\begin{array}{l}\text { Global pheromone } \\
\text { update, } \tau_{02}\end{array}$ & $\begin{array}{c}\text { Probability, } \\
\mathrm{P}_{03}\end{array}$ & $\begin{array}{l}\text { Global pheromone } \\
\text { update, } \tau_{03}\end{array}$ & $\begin{array}{c}\text { Probability, } \\
\mathrm{P}_{04}\end{array}$ & $\begin{array}{c}\text { Global pheromone } \\
\text { update, } \tau_{04}\end{array}$ \\
\hline 1 & 0.3322 & 0.5071 & 0.3354 & 0.5500 & 0.3324 & 0.5152 \\
\hline 2 & 0.3868 & 0.1455 & 0.2577 & 0.2125 & 0.3555 & 0.1864 \\
\hline 3 & 0.4768 & 0.0799 & 0.2288 & 0.1563 & 0.2944 & 0.1083 \\
\hline 4 & 0.5516 & 0.0471 & 0.1468 & 0.1281 & 0.3016 & 0.0693 \\
\hline 5 & 0.6252 & 0.0307 & 0.0856 & 0.1141 & 0.2892 & 0.0498 \\
\hline 6 & 0.6881 & 0.0225 & 0.0504 & 0.1070 & 0.2615 & 0.0401 \\
\hline 7 & 0.7352 & 0.0184 & 0.0328 & 0.1035 & 0.2319 & 0.0352 \\
\hline 8 & 0.7661 & 0.0163 & 0.0244 & 0.1018 & 0.2094 & 0.0327 \\
\hline 9 & 0.7842 & 0.0153 & 0.0204 & 0.1009 & 0.1954 & 0.0315 \\
\hline
\end{tabular}

Table 8. Solution of Critical Path using ACO

\begin{tabular}{|c|c|c|c|c|c|c|c|}
\hline \multicolumn{4}{|c|}{ NETWORK } & \multicolumn{2}{|c|}{ RELATIONSHIP } & \multicolumn{2}{|c|}{ RESULT } \\
\hline No & Start node & End node & Duration & $\begin{array}{c}\text { Original pheromone } \\
\text { level }\end{array}$ & $\begin{array}{c}\text { Final pheromone level } \\
\text { (after iteration) }\end{array}$ & Probability & $\begin{array}{l}\text { Critical } \\
\text { activity }\end{array}$ \\
\hline A & 0 & 2 & 70 & 0.0143 & 0.0148 & 0.7941 & YES \\
\hline $\mathrm{B}$ & 0 & 3 & 10 & 0.0100 & 0.1004 & 0.0185 & No \\
\hline $\mathrm{C}$ & 0 & 4 & 33 & 0.0303 & 0.0309 & 0.1875 & No \\
\hline $\mathrm{D}$ & 1 & 4 & 29 & 0.0345 & 0.3185 & 0.0350 & No \\
\hline $\mathrm{E}$ & 1 & 5 & 43 & 0.0232 & 0.6815 & 0.0237 & No \\
\hline $\mathrm{F}$ & 2 & 3 & 70 & 0.0143 & 0.0148 & 0.3486 & YES \\
\hline $\mathrm{G}$ & 2 & 6 & 67 & 0.0149 & 0.0154 & 0.3211 & No \\
\hline $\mathrm{H}$ & 2 & 7 & 68 & 0.0147 & 0.0152 & 0.3302 & No \\
\hline $\mathrm{I}$ & 3 & 7 & 67 & 0.0149 & 0.0154 & 1 & YES \\
\hline $\mathrm{J}$ & 4 & 6 & 37 & 0.0270 & 0.0275 & 1 & No \\
\hline $\mathrm{K}$ & 5 & 7 & 11 & 0.0909 & 0.0914 & 1 & No \\
\hline $\mathrm{L}$ & 6 & 7 & 29 & 0.0345 & 0.3495 & 1 & No \\
\hline
\end{tabular}




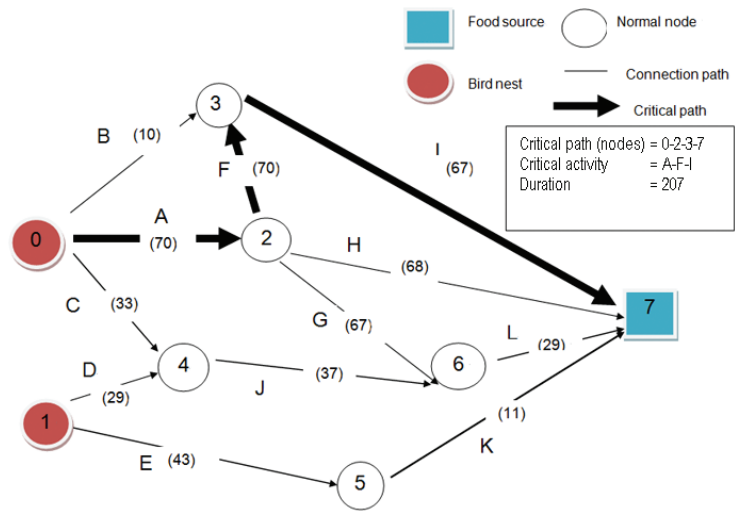

Fig. 4. Network topology result in Step 1 using CSAM-ACO acceleration model

\section{Step 2: Selection of critical activities}

After the critical path was found in Step 1, the $2^{\text {nd }}$ step was to select the critical activity in the critical path. The critical activity is splitting down to be scheduled in a more detailed form. In order to accelerate the construction process, the duration of the critical activity has to be shortened. The selected critical activity was to be accelerated from the original duration at 70 .

\section{Step 3: Splitting down of selected critical activity}

The list of splitting tasks is shown in Table 9.

Table 9. Activity table for splitting tasks

\begin{tabular}{|c|c|c|c|c|}
\hline No & Activity & 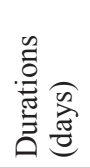 & 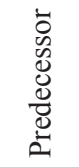 & 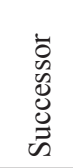 \\
\hline A: $0-1$ & Stripping form & 4 & - & $\mathrm{C}, \mathrm{D}$ \\
\hline B: $0-2$ & Precast façade fixing & 13 & - & $\mathrm{E}$ \\
\hline C: $1-5$ & Beam and slab steel fixing & 21 & A & $\mathrm{I}, \mathrm{J}$ \\
\hline $\mathrm{D}: 1-4$ & Semi-precast slab fixing & 28 & $\mathrm{~A}$ & $\mathrm{H}$ \\
\hline E: $2-3$ & Wall steel fixing & 12 & $\mathrm{~B}$ & $\mathrm{~F}, \mathrm{G}$ \\
\hline F: $3-5$ & Wall form fixing & 12 & $\mathrm{E}$ & $\mathrm{I}, \mathrm{J}$ \\
\hline G: $3-7$ & Wall concreting & 11 & $\mathrm{E}$ & - \\
\hline H: 4-7 & Slab form fixing & 15 & $\mathrm{D}$ & - \\
\hline I: $5-6$ & $\begin{array}{l}\text { Electrical conduit installation } \\
\text { phase } 1\end{array}$ & 13 & $\mathrm{C}, \mathrm{F}$ & K \\
\hline $\mathrm{J}: 5-7$ & $\begin{array}{l}\text { Electrical conduit installation } \\
\text { phase } 2\end{array}$ & 10 & $\mathrm{C}, \mathrm{F}$ & - \\
\hline K: $6-7$ & Beam and slab concreting & 13 & $\mathrm{I}$ & - \\
\hline
\end{tabular}

After splitting down the critical activity into smaller tasks, the original duration of the activity was shortened from 70 to 63. It was scheduled to repetitive tasks or separate tasks which could be conducted concurrently. Eventually, the duration was shortened with more detailed tasks, which provide a clearer picture of the tasks sequences. Same as the previous session, a network topology for these tasks was constructed. The topology was made up with 8 nodes and 11 nodal connections. In the 8 nodes, there are 1 ant nest, 1 food source and 6 regular

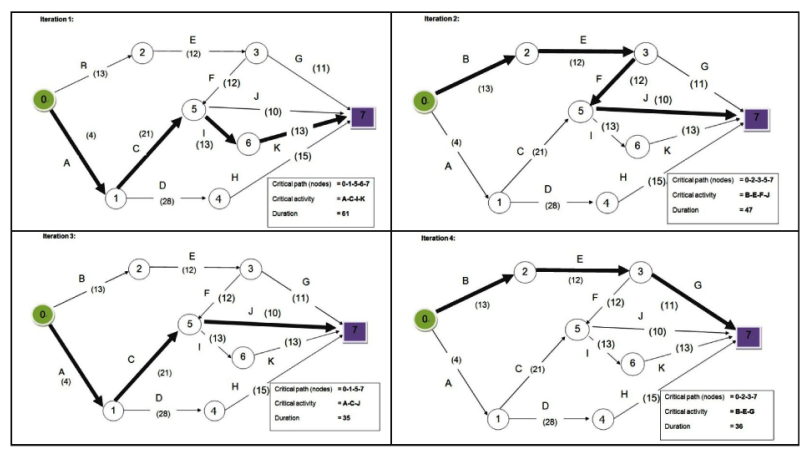

Fig. 5. New network topology for Iteration 1 to Iteration 4

nodes. The constructed new network topology for the detailed activity in the framing work is shown in Figure 5.

\section{Step 4: Finding new critical path}

After the new network topology was constructed with the splitting tasks and durations, a new critical path was found requiring higher attention for resource allocation. The calculation in this step was similar as that in the Step 1.

\section{By Traditional CPM}

The calculated ES, EF, LS, LF, and total float were tabulated in Table 10. The critical path with zero total float is determined. The determined critical path identified by CPM was compared with the result of ACO. The critical path was formed by $0-2,2-3,3-5,5-6$ and 6-7. Thus, the longest duration of the task of the framing works is $13+12+12+13+13=63$. It indicates that the original duration of 70 was reduced to 63 , which is the longest duration of the activity.

\section{By ACO Algorithm}

The new network topology for Iteration 1 to Iteration 4 is shown in Figure 5. The new topology solution was calculated using the same equations as in Step 1. The computational result using ACO is tabulated in Table 11. The longest continuous path of these activities was identified and the activities of $0-2,1-4,3-5,5-6$ and $6-7$ are the critical activities with the critical path duration at 63 . The network topology of final solution was shown in Figure 6. It proved that the splitting down of framing works into smaller tasks reduced the duration by 7 days.

\section{Discussion and comparison of CSAM-ACO with CPM and previous studies}

Though Adeli and Karim (2001) believe, that the traditional CPM tool performs well in construction scheduling, the trial run conducted in this study proved that the developed CSAM-ACO model is more favorable compared with CPM. CSAM-ACO is able to calculate the longest node-to-node path, and the calculation can be done concurrently for different nodes and a big number of activities and resource allocation. In addition, the du- 
Table 10. Solution of new critical path for splitting tasks using CPM

\begin{tabular}{c|c|c|c|c|c|c|c|c|c|c}
\hline Code & Start node & End node & Duration & Successor & ED & EF & LS & LF & TF & CA \\
\hline A & 0 & 1 & 4 & C, D & 0 & 4 & 12 & 16 & 12 & No \\
\hline B & 0 & 2 & 13 & E & 0 & 13 & 0 & 13 & 0 & YES \\
\hline C & 1 & 5 & 21 & I, J & 4 & 25 & 16 & 37 & 12 & No \\
\hline D & 1 & 4 & 28 & H & 4 & 32 & 20 & 48 & 16 & No \\
\hline E & 2 & 3 & 12 & F, G & 13 & 25 & 13 & 25 & 0 & YES \\
\hline F & 3 & 5 & 12 & I, J & 25 & 37 & 25 & 37 & 0 & YES \\
\hline G & 3 & 7 & 11 & - & 25 & 36 & 52 & 63 & 27 & No \\
\hline H & 4 & 7 & 15 & - & 32 & 47 & 48 & 63 & 16 & No \\
\hline I & 5 & 6 & 13 & K & 37 & 50 & 37 & 50 & 0 & YES \\
\hline J & 5 & 7 & 10 & - & 37 & 47 & 53 & 63 & 16 & No \\
\hline
\end{tabular}

Table 11. Solution of splitting tasks using ACO

\begin{tabular}{|c|c|c|c|c|c|c|c|c|}
\hline \multicolumn{5}{|c|}{ Network } & \multicolumn{2}{|c|}{ Relationship } & \multicolumn{2}{|c|}{ Result } \\
\hline No & ID & Start node & End node & Duration & $\begin{array}{c}\text { Original pheromone } \\
\text { level }\end{array}$ & $\begin{array}{c}\text { Final pheromone } \\
\text { level }\end{array}$ & Probability & $\begin{array}{l}\text { Critical } \\
\text { activity }\end{array}$ \\
\hline $\mathrm{A}$ & 1 & 0 & 1 & 4 & 0.2500 & 0.2504 & 0.0924 & No \\
\hline B & 2 & 0 & 2 & 13 & 0.0769 & 0.0774 & 0.9076 & YES \\
\hline $\mathrm{C}$ & 3 & 1 & 5 & 21 & 0.0476 & 0.0481 & 0.3638 & No \\
\hline $\mathrm{D}$ & 4 & 1 & 4 & 28 & 0.0357 & 0.0362 & 0.6362 & No \\
\hline $\mathrm{E}$ & 5 & 2 & 3 & 12 & 0.0833 & 0.0838 & 1 & YES \\
\hline $\mathrm{F}$ & 6 & 3 & 5 & 12 & 0.0909 & 0.0838 & 0.5426 & YES \\
\hline $\mathrm{G}$ & 7 & 3 & 7 & 11 & 0.0833 & 0.0914 & 0.4574 & No \\
\hline $\mathrm{H}$ & 8 & 4 & 7 & 15 & 0.0667 & 0.0671 & 1 & $\mathrm{No}$ \\
\hline I & 9 & 5 & 6 & 13 & 0.1000 & 0.0774 & 0.6259 & Yes \\
\hline $\mathrm{J}$ & 10 & 5 & 7 & 10 & 0.0769 & 0.1004 & 0.3741 & No \\
\hline $\mathrm{K}$ & 11 & 6 & 7 & 13 & 0.0769 & 0.0774 & 1 & YES \\
\hline
\end{tabular}

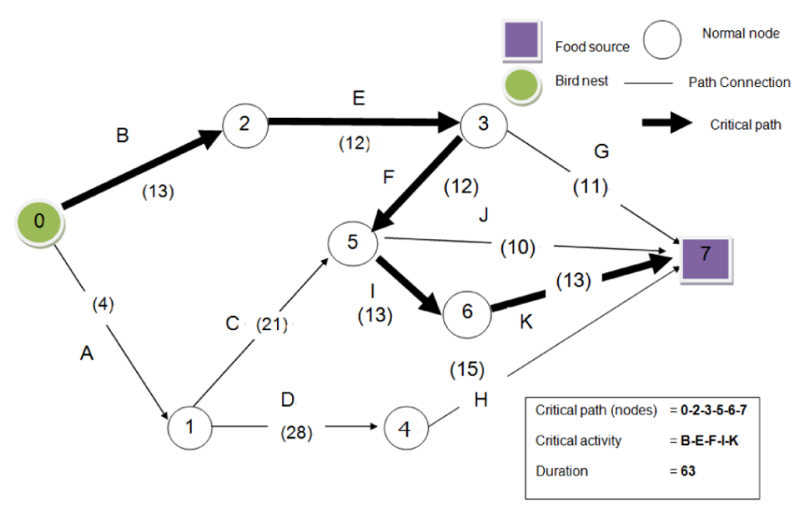

Fig. 6. New network topology for final solution

ration of the activity is shortened by splitting down the critical activity so that the resources allocated on the new found critical path could assist in accelerating the entire schedule. Besides, compared with the previous study conducted by Christodoulou (2009) who introduced ACO for project scheduling, this study developed a construction schedule acceleration model using the self-developed ACO algorithm processes. The concepts of both ACO and CPM in finding critical path were integrated in the schedule acceleration model for a more precise resource allocation. The uniqueness of this study was also incar- nated by the trial run of CSAM-ACO under a real case. Besides its prominent advantages, the developed CSAM$\mathrm{ACO}$ has yet some limitations, for instance the splitting down process of the critical activities is rather time-consuming. Furthermore, CSAM-ACO involves two stages of computation in finding the critical path which causes double calculation.

\section{Conclusions and recommendations}

The developed model CSAM-ACO targets on schedule acceleration by allocating resources on the newly found critical path after two stages of computation. The trial run proves CSAM-ACO is not only able to increase the probability of completing a delayed project within the stipulated time but also able to satisfy the request of earlier completion of a project. It accelerates the schedule and shortens the project duration where time is constraint. Breaking down of the critical activity provides a clear picture of the construction process so that it provides more precise resource allocation than CPM does by working on those smaller tasks in the critical activity. In further study, the splitting down process of critical activities in CSAM-ACO is to be optimized. Besides, by taking into consideration that the Industrialized Building System (IBS) is highly implemented in the construction sector, 
which is for the same purpose of time saving, a tailored CSAM-ACO is highly recommended to be developed for IBS projects.

\section{Acknowledgements}

Authors are thankful to University of Malaya for financial support through High Impact Research grant J-1300173885 "HIR (UM.C/625/1/HIR/248)".

\section{References}

Adeli, H.; Karim, A. 2001. Construction scheduling, cost optimization and management. New York: CRC Press. 352 p.

Al Salami, N. M. A. 2009. Ant colony optimization algorithms, UbiCC Journal 4(3): 822-826.

Alcala, R.; Casillas, J.; Cordon, O.; Herrera, F. 2001. Improvement to the cooperative rules methodology by using ant colony system algorisms, Mathware \& Soft Computing 8(3): 321-335.

Blum, C.; Dorigo, M. 2004. The hyper-cube framework for ant colony optimization, IEEE Transactions on Systems, Man, and Cybernetics, Part B: Cybernetics 34(2): 1161-1172. http://dx.doi.org/10.1109/TSMCB.2003.821450

Blum, C.; Lopez-Ibanez, M. 2010. Beam-ACO for the travelling salesman problem with time windows, Computers and Operations Research 37(9): 1570-1583. http://dx.doi.org/10.1016/j.cor.2009.11.015

Bullnheimer, B.; Hartl, R.; Strauss, C. 1997. A new rankbased version of the Ant System: A computational study, Central European Journal for Operations Research and Economics 7(1): 25-38.

Campos, L. M.; Gamez, J. A.; Puerta, J. M. 2002. Learning Bayesian networks by ant colony optimization: searching in two different places, Mathware \& Soft Computing 9(3): $1-18$.

Caro, G. D.; Dorigo, M. 1998. AntNet: distributed stigmergetic control for communications networks, Journal of Artificial Intelligence Research 9(1): 317-365.

Christodoulou, S. 2009. Construction imitating ants: resourceunconstrained scheduling with artificial ants, Automation in Construction 18(3): 285-293. http://dx.doi.org/10.1016/j.autcon.2008.09.005

Cordon, O.; Herrera, F.; Stutzle, T. 2002. A review on the ant colony optimization metaheuristic: basis, models, and new trends, Matyhware \& Soft Computing 9: 1-35.

Costa, D.; Hertz, A. 1997. Ants can colour graphs, The Journal of the Operational Research Society 48(3): 295-305. http://dx.doi.org/10.1057/palgrave.jors.2600357

Dorigo, M. 1992. Ottimizzazione, apprendimento automatico, ed algoritmi basati su metafora naturale [Optimization, learning and natural algorithms]: $\mathrm{PhD}$ thesis. Politecnico di Milano, Italy (in Italian).

Dorigo, M.; Blum, C. 2005. Ant colony optimization: a survey, Theoretical Computer Science 344(2-3): 243-278. http://dx.doi.org/10.1016/j.tcs.2005.05.020

Dorigo, M.; Bonabeau, E.; Theraulaz, G. 2000. Ant algorithms and stigmergy, Future Generation Computer Systems 16(8): 851-871. http://dx.doi.org/10.1016/S0167-739X(00)00042-X

Dorigo, M.; Caro, G.; Gambardella, L. M. 1999. Ant algorithms for discrete optimization, Artificial Life 5(2): 137-172. http://dx.doi.org/10.1162/106454699568728

Dorigo, M.; Gambardella, L. M. 1997. Ant colony system: a cooperative learning approach to the traveling salesman problem, IEEE Transactions on Evolutionary Computation 1(1): 53-66. http://dx.doi.org/10.1109/4235.585892
Dorigo, M.; Maniezzo, V.; Colorni, A. 1996. Ant System: optimization by a colony of cooperating agents, IEEE Transactions on Systems, Man, and Cybernetics, Part B: Cybernetics 26(1): 29-41. http://dx.doi.org/10.1109/3477.484436

Dorigo, M.; Stutzle, T. 2004. Ant colony optimization. London: MIT Press. 305 p. http://dx.doi.org/10.1007/b99492

Duan, Q.; Liao, T. W. 2010. Improved ant colony optimization algorithms for determining project critical paths, Automation in Construction 19(6): 676-693. http://dx.doi.org/10.1016/j.autcon.2010.02.012

Gambardella, L. M.; Dorigo, M. 1996. Solving symmetric and asymmetric TSPs by ant colonies, in Proc. of the IEEE Conference on Evolutionary Computation (ICEC'96), 20-22 May 1996, Nagoya, Japan. New York: IEEE Press, 622-627. http://dx.doi.org/10.1109/ICEC.1996.542672

Hani, Y.; Amodeo, L.; Yalaoui, F.; Chen, H. 2007. Ant colony optimization for solving an industrial layout problem, European Journal of Operational Research 183(2): 633642. http://dx.doi.org/10.1016/j.ejor.2006.10.032

Hoseini, P.; Shayesteh, M. G. 2013. Efficient contrast enhancement of images using hybrid ant colony optimisation, genetic algorithm, and simulated annealing, Digital Signal Processing 23(3): 879-893. http://dx.doi.org/10.1016/j.dsp.2012.12.011

Kloppenborg, T. J. 2009. Project management: a contemporary approach. London: Asia Cengage Learning. 480 p.

Kong, M.; Tian, P. 2006. A direct application of ant colony optimization to function optimization problem in continuous domain, Lecture Notes in Computer Science 4150: 324331. http://dx.doi.org/10.1007/11839088_29

Lakshminarayanan, S.; Gaurav, A.; Arun, C. 2011. Time-costrisk trade off using ant colony optimization, Journal of Construction in Developing Countries 16(1): 1-14.

Lam, K. C.; Ning, X.; Ng, T. 2007. The application of the ant colony optimization algorithm to the construction site layout planning problem, Construction Management and Economics 25(4): 359-374.

http://dx.doi.org/10.1080/01446190600972870

Li, X. Y.; Tian, P. 2006. An ant colony system for the open vehicle routing problem, Lecture Notes in Computer Science 4150: 356-363. http://dx.doi.org/10.1007/11839088_33

Lopez-Ibanez, M.; Blum, C. 2010. Beam-ACO for the travelling salesman problem with time windows, Computers \& Operations Research 37(9): 1570-1583. http://dx.doi.org/10.1016/j.cor.2009.11.015

Maniezzo, V.; Colorni, A. 1999. The Ant System applied to the quadratic assignment problem, IEEE Transactions on Knowledge and Data Engineering 11(5): 769-778. http://dx.doi.org/10.1109/69.806935

Mateos, C.; Pacini, E.; Garino, C. G. 2013. An ACO-inspired algorithm for minimizing weighted flowtime in cloud-based parameter sweep experiments, Advances in Engineering Software 56: 38-50. http://dx.doi.org/10.1016/j.advengsoft.2012.11.011

Mubarak, S. 2010. Scheduling and control. $2^{\text {nd }}$ ed. Canada: Wiley. 480 p. http://dx.doi.org/10.1002/9780470912171

Naylor, H. F. W. 1995. Construction project management: planning and scheduling. New York: Delmar. 289 p.

Ng, S. T.; Zhang, Y. 2008. Optimizing construction time and cost using ant colony optimization approach, Journal of Construction Engineering and Management 134(9): 721728 .

http://dx.doi.org/10.1061/(ASCE)0733-9364(2008)134:9(721)

Parpinelli, R. S.; Lopes, H. S.; Freitas, A. A. 2002. Data mining with an ant colony optimization algorithm, IEEE Transactions on Evolutionary Computation 6(4): 321332. http://dx.doi.org/10.1109/TEVC.2002.802452 
Sauter, D. 2011. Landscape construction. New York: Maxwell. $640 \mathrm{p}$.

Schoonderwoerd, R.; Holland, O.; Bruten, J.; Rothkrantz, L. 1996. Ant-based load balancing in telecommunications networks, Adaptive Behavior 5(2): 169-207. http://dx.doi.org/10.1177/105971239700500203

Srour, I. M.; Abdul-Malak, M. A. U.; Yassine, A. A.; Ramadan, M. 2013. A methodology for scheduling overlapped design activities based on dependency information, Automation in Construction 29: 1-11.

http://dx.doi.org/10.1016/j.autcon.2012.08.001
Stutzle, T.; Hoos, H. H. 2000. MAX-MIN ant system, Future Generation Computer Systems 16(8): 889-914. http://dx.doi.org/10.1016/S0167-739X(00)00043-1

Wiesemann, W.; Stutzle, T. 2006. Iterated ants: an experimental study for the quadratic assignment problem, Lecture Notes in Computer Science 4150: 179-190. http://dx.doi.org/10.1007/11839088_16

Zundel, M. 2013. Walking to learn: rethinking reflection for management learning, Management Learning 44(2): 109126. http://dx.doi.org/10.1177/1350507612440231

Chen WANG. He is a Distinguished Professor in Faculty of Civil Engineering, Huaqiao University, China, and also an Associate Professor of Construction Innovation and Project Management in the Faculty of Built Environment, University of Malaya. He was a senior engineer of China State Construction Engineering Corporation (CSCEC), which is the main contractor of the 2008 Olympics Beijing National Aquatics Center known as "Water Cube". His research interests include Vertical Greenery System (VGS), Mathematics Modeling for Civil Engineering, swarm intelligence, Ant Colony Optimization (ACO), Fuzzy-QFD, Tensile Membrane Steel Structure, Vertical Greenery Systems, Repertory Grid, sustainability in construction management, international BOT projects, energy conservation, and building integrated solar application, supported by his vast publications. He is an IEEE member (U.S.), RICS member (U.K.), and also a perpetual member of The Chinese Research Institute of Construction Management (CRIOCM), Hong Kong (International).

Hamzah ABDUL-RAHMAN. Dip. Bldg (UiTM), BSc (Hons) Central Missouri State University, M.Sc. University of Florida, PhD University of Manchester Institute of Science and Technology, FRICS, MCIOB, MIVMM, is currently the Vice-Chancellor of the International University of Malaya-Wales (IUMW), which is one of the world's first Malaysia-British university among research led universities. He has served as the Deputy Vice Chancellor (Research \& Innovation), University of Malaya and a full professor in the Faculty of Built Environment, University of Malaya. He has served as the Deputy Vice Chancellor for Development and Estate Management in charge of development policies and construction projects from 1996 to 2003, and the Deputy Vice Chancellor (Academic \& International) from 2009-2010 in University of Malaya. He holds a PhD degree from the University of Manchester Institute of Science and Technology (UMIST, UK), MSc from University of Florida and BSc (Hons) from Central Missouri State University, Dip. Bldg (UiTM). His research interests include the construction innovation \& sustainability, project \& facility management, building energy efficiency, industrialized building system (IBS), and renewable energy application in buildings, supported by his vast publications. He is also a fellow member of the Chartered Institute of Surveyors, United Kingdom (International).

Pui See CHOW. Is a research fellow in the Centre of Construction Facility Management, Faculty of Built Environment, University of Malaya. Her expertise is in ACO and Mathematics Modelling. 